\title{
Klebsiella pneumoniae necrotizing fasciitis of the leg in an elderly French woman
}

\author{
This article was published in the following Dove Press journal: \\ Clinical Interventions in Aging \\ 18 July 2014 \\ Number of times this article has been viewed
}

\author{
Marguerite Monié \\ Laurence Drieux ${ }^{2-4}$ \\ Bernadette Nzili' \\ Michèle Dicko ${ }^{5}$ \\ Catherine Goursot ${ }^{\prime}$ \\ Sandrine Greffard ${ }^{6}$ \\ Dominique Decré ${ }^{3,4,7}$ \\ Anthony Mézière' \\ 'Assistance Publique-Hôpitaux \\ de Paris (AP-HP), GHU Pitié \\ Salpêtrière-Charles Foix, site Charles \\ Foix, Service de Soins de Suite et \\ Réadaptation orthogériatrique \\ et polyvalent, Fondation d'Heur \\ et Chemin Delatour, Ivry s/Seine, \\ ${ }^{2}$ Assistance Publique-Hôpitaux \\ de Paris, Hôpital Charles-Foix, \\ Bactériologie-Hygiène, Paris, \\ ${ }^{3}$ Sorbonne Universités, UPMC Univ \\ Paris 06, CR7, Centre d'Immunologie \\ et des Maladies Infectieuses, \\ CIMI, team EI 3 (Bacteriology), \\ Paris, ${ }^{4}$ INSERM, UII 35 , Centre \\ d'Immunologie et des Maladies \\ Infectieuses, CIMI, team EI 3 \\ (Bacteriology), Paris, ${ }^{5} \mathrm{AP}-\mathrm{HP}, \mathrm{GHU}$ \\ Henri Mondor, Département de \\ Médecine Interne et Gériatrie, \\ Créteil, ${ }^{6} \mathrm{AP}-\mathrm{HP}, \mathrm{GHU}$ Pitié \\ Salpêtrière-Charles Foix, site Pitié \\ Salpêtrière, Service de Médecine \\ Gériatrique, Paris, ${ }^{7}$ AP-HP, Hôpital \\ Saint-Antoine, Bactériologie-Hygiène, \\ Paris, France
}

Correspondence: Anthony Mézière Assistance Publique-Hôpitaux de Paris, GHU Pitié Salpêtrière-Charles Foix, site Charles Foix, Service de Soins de Suite et Réadaptation orthogériatrique et polyvalent, Fondation d'Heur et Chemin Delatour, 7 avenue de la République, 94205 Ivry s/Seine, Paris, France

$\mathrm{Tel}+33$ I 49594585

Fax +33I 49594943

Email anthony.meziere@cfx.aphp.fr
Abstract: Klebsiella pneumoniae necrotizing fasciitis is a rare infection in regions outside of Asia. Here, we present a case of necrotizing fasciitis of the leg caused by K. pneumoniae in a 92-year-old French woman hospitalized in a geriatric rehabilitation unit. The patient initially presented with dermohypodermitis of the leg that developed from a dirty wound following a fall. A few hours later, this painful injury extended to the entire lower limb, with purplish discoloration of the skin, bullae, and necrosis. Septic shock rapidly appeared and the patient died 9 hours after the onset of symptoms. The patient was Caucasian, with no history of travel to Asia or any underlying disease. Computed tomography revealed no infectious metastatic loci. Blood cultures showed growth of capsular serotype K2 K. pneumoniae strains with virulence factors RmpA, yersiniabactin and aerobactin. This rare and fatal case of necrotizing fasciitis caused by a virulent strain of $K$. pneumoniae occurred in a hospitalized elderly woman without risk factors. Clinicians and geriatricians in particular should be aware of this important albeit unusual differential diagnosis.

Keywords: necrotizing fasciitis, Klebsiella pneumoniae, elderly

\section{Introduction}

First described by Hippocrates in the fifth century BC, the term "necrotizing fasciitis" was coined by Wilson in 1952. ${ }^{1,2}$ Necrotizing fasciitis is an acute, progressive, invasive, and severe infection that spreads along fascial planes, producing inflammation and necrosis of the adjacent muscle, subcutaneous fat, and skin. The incidence of necrotizing fasciitis is about 4 per million world population, and mortality rates as high as $73 \%$ are noted. ${ }^{3}$ Necrotizing fasciitis is classified into two types: type 1 polymicrobial necrotizing fasciitis (a mix of aerobic and anaerobic bacteria) and type 2 monomicrobial necrotizing fasciitis, caused mainly by Streptococcus pyogenes but also by Klebsiella pneumoniae. ${ }^{4}$ Initial empiric broad-spectrum antibiotic coverage is needed in cases of necrotizing fasciitis, directed against aerobic Gram-positive cocci, Gram-negative rods, and a variety of anaerobes as recommended by the Infectious Diseases Society of America. ${ }^{5} \mathrm{~K}$. pneumoniae is an enteric Gram-negative rod mostly implicated in hospital-acquired urinary tract infections, pneumonia, septicemia, and intra-abdominal infections. In Asia, K. pneumoniae necrotizing fasciitis was reported for the first time in 1996 in patients with comorbidities including diabetes mellitus, hepatobiliary disease, malignancy, and acquired immunodeficiency syndrome. ${ }^{6-11}$

\section{Case report}

A 92-year-old French woman with a history of hypertension, atrial fibrillation, and dementia with Lewy bodies (Mini-Mental State Examination score 23/30) was initially admitted to an acute geriatric unit at La Pitié Salpêtrière University Hospital, 
Paris, France, following regular falls at home. Her falls were due to sick sinus syndrome (bradycardia of 30 beats per minute, necessitating implantation of a pacemaker), and orthostatic hypotension. The patient was then transferred to a geriatric rehabilitation care unit at Charles Foix Hospital in the Paris area. She was clinically stable during her stay in the rehabilitation unit, and her medication was rabeprazole and mianserin. An initially clean $2 \mathrm{~cm}$ wound was noticed on the right leg upon her arrival at the rehabilitation care unit. Initially no fever or inflammation was reported, and the wound was managed with local antiseptic dressings and daily monitoring.

At 9 am on day 28, the patient developed fever with erythema and edema of the right leg, and lymphangitis ascending from the wound. Dermohypodermitis was diagnosed and antimicrobial treatment was started with intravenous amoxicillin 3,000 mg/day. A venous Doppler was performed and did not show thrombosis. At 3 pm, the injury extended to the entire lower limb, with purplish discoloration of the skin, bullae, and necrosis. The patient complained of severe pain at this time, requiring administration of morphine. Leg movements were limited. This was suggestive of necrotizing fasciitis of the right leg.

Blood cultures were performed and empiric broadspectrum antibiotic therapy was commenced. Amoxicillin was switched for an intravenous combination of piperacillin $8 \mathrm{~g} /$ day and tazobactam $1 \mathrm{~g} /$ day and intravenous gentamicin $150 \mathrm{mg} /$ day. The patient's condition rapidly deteriorated. Vitals included a blood pressure of $93 / 50 \mathrm{mmHg}$, a heart rate of 91 beats per minute, a body temperature of $34.3^{\circ} \mathrm{C}$, a respiratory rate of 32 breaths per minute, and an oxygen saturation of $84 \%$ in ambient air. Reduced consciousness was noted. In the context of a distended abdomen and dyspnea, a computed tomography scan was performed, but revealed neither pneumoniae nor abdominal or pelvic infection.

Laboratory findings were as follows: white cell count, 4.6 cells $/ \mathrm{mm}^{3}$; hemoglobin, $13.0 \mathrm{~g} / \mathrm{dL}$; platelet count, $15.1 \times 10^{4}$ cells $/ \mathrm{mm}^{3}$; C-reactive protein, $70 \mathrm{mg} / \mathrm{dL}$; blood glucose, $1.4 \mathrm{mmol} / \mathrm{L}$; procalcitonin, $43 \mathrm{ng} / \mathrm{mL}$; troponin, $3.73 \mu \mathrm{g} / \mathrm{L} ; \mathrm{pH} 7.19 ; \mathrm{HCO}_{3}, 14.4 \mathrm{mmol} / \mathrm{L}$; and blood lactate, $9.0 \mathrm{mmol} / \mathrm{L}$. Urine analysis showed no infection.

The patient developed septic shock requiring fluid challenge. Extension of the necrotic disease process to the entire lower limb and her precarious medical condition prompted transfer to La Pitié Salpêtrière Hospital for urgent aggressive surgical debridement of her necrotic tissues and appropriate multimodal therapy, including mechanical ventilation, inotropic support, and antibiotic administration in an intensive care unit. Unfortunately, the patient died of septic shock at 6 pm upon arrival at La Pitié Salpêtrière Hospital.

\section{Bacterial investigation}

Blood cultures were incubated in an automated BacT/ ALERT system (Organon Teknika, bioMérieux, Inc, Durham, NC, USA) and grew $K$. pneumoniae. On blood agar, the isolate grew as hypermucoviscous colonies and showed a positive string test (Figure 1). This isolate harbored the wild-type resistant phenotype of $K$. pneumoniae, ie, resistance to amoxicillin, piperacillin, and ticarcillin. A multiplex polymerase chain reaction was performed to determine the capsular serotype of the strain. ${ }^{12,13}$ The presence of known virulence factors was determined by polymerase chain reaction using primers described elsewhere. ${ }^{14}$ Two reference strains of capsular serotypes K1 (NTUH K2044) and K2 (CG43) were used as controls. ${ }^{15}$ The isolate was the capsular K2 serotype and carried the regulator of the mucoid phenotype RmpA, and two siderophores, ie, aerobactin and yersiniabactin. Multilocus sequence typing was performed using the international multilocus sequence typing scheme from the Institut Pasteur, Paris, France (http://www.pasteur.fr/mlst) and revealed that the isolate belonged to sequence type ST86.

\section{Discussion}

We report here a rare French case of necrotizing fasciitis caused by $K$. pneumoniae, which is a common causative pathogen in monomicrobial necrotizing fasciitis in Asia, especially in Taiwan, in patients with risk factors. ${ }^{16,17}$ Some cases have been documented in Europe and the USA, mainly in patients who had travelled to Asia or were of Asian descent. ${ }^{7,8,18-20}$ The majority of cases described to date have been in Asians, raising the question of a genetic predisposition versus geographic strain acquisition. ${ }^{21}$ Our patient was

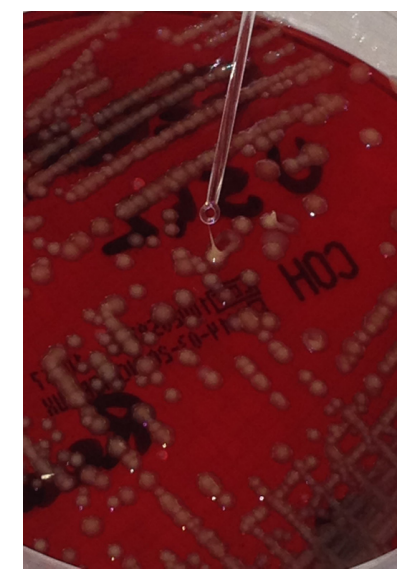

Figure I Hypermucoviscous Klebsiella pneumoniae colonies with positive string test. 
a Caucasian woman who had not visited an endemic Asian area before the onset of infection. However, on review of her social history, she had lived in Paris' Chinatown and used to go to Asian restaurants in her neighborhood one year prior to her presentation. Her grandson, whom she met with frequently, used to travel to China for work. Is it possible that her acquisition of this $K$. pneumoniae was via food transmission or cross transmission? Epidemiologic factors are still being defined. Colonization, particularly intestinal colonization, appears to be a critical step leading to infection, although the route of entry remains unclear. Unfortunately, the patient was not screened for gut colonization with $K$. pneumoniae.

Moreover, this patient had $K$. pneumoniae necrotizing fasciitis without predisposing medical factors identified by her history, biology, or imaging (computed tomography).$^{7-11}$ No apparent underlying disease was identified, except for her very advanced age. Reasons for an increased susceptibility to $K$. pneumoniae necrotizing fasciitis in the elderly could include immunosenescence and malnutrition, as well as a large number of age-associated physiological changes. ${ }^{22,23}$ To the best of our knowledge, K. pneumoniae necrotizing fasciitis has not been reported previously in such an elderly patient. ${ }^{6,9,16,18,20}$

In our patient, the necrotizing fasciitis occurred during hospitalization in a geriatric rehabilitation care unit and was considered health care-associated. Less than 12 hours elapsed between the onset of symptoms and the fatal outcome. This fulminant case is consistent with previous reports of monomicrobial K. pneumoniae necrotizing fasciitis rapidly leading to septic shock (within 72 hours). ${ }^{24}$ As in other patients, systemic complications resulted in a fatal outcome, with no benefit from prompt and appropriate treatment with antibiotics and surgical debridement. ${ }^{25}$ Advanced age, anemia, and thrombocytopenia are considered to be risk factors for mortality, ${ }^{26}$ and $K$. pneumoniae necrotizing fasciitis has a poor prognosis in the elderly, as highlighted in this report. Important pharmacokinetic and pharmacodynamic changes also occur with advancing age. ${ }^{27}$

Although no skin biopsy was performed, the leg wound was suspected to be the primary site of infection. The preceding local injury was probably the result of minor trauma in this patient, who was known to have falls. A systematic study of monomicrobial $K$. pneumoniae necrotizing fasciitis showed that the initial infectious site was often on the lower extremities $;{ }^{16}$ however, no preceding local factor was identified in half of the cases, and the infection showed a hematogenous spread, unlike the present case. ${ }^{16,18}$

The bacteriological findings of a K2 serotype and virulence factors RmpA, yersiniabactin and aerobactin are consistent with the epidemiological data. The K2 serotype reported in this case seems to be observed more often outside of Asia than the K1 serotype. ${ }^{28}$ The K2 serotype also seems less likely to be responsible for distant abscesses than $\mathrm{K} 1 .{ }^{29}$ Our case can be added to the previous ones, and underscores the invasive and severe infectious nature of K2 K. pneumoniae. ${ }^{18,30,31}$

\section{Conclusion}

Here we report a rare case of fatal necrotizing fasciitis from a leg wound caused by virulent $K$. pneumoniae in a 92-year-old French woman. No risk factors were identified. Advanced age, already considered to indicate a poor prognosis, could be a risk factor for developing $K$. pneumoniae necrotizing fasciitis. A combination of our aging population and increased travel may explain the spread of this emerging worldwide infectious disease. ${ }^{32,33}$ Clinicians and geriatricians in particular should be aware that this unusual emerging pathogen may be involved in the pathogenesis of necrotizing fasciitis and requires prompt and appropriate therapy. ${ }^{32,34}$

\section{Acknowledgments}

Reference strains were kindly provided by $\mathrm{S}$ Brisse, Institut Pasteur, Paris, France. The authors thank S Wilks and $\mathrm{S}$ Curtis for English editing and language revision.

\section{Disclosure}

The authors report no conflicts of interest in this work.

\section{References}

1. Descamps V, Aitken J, Lee MG. Hippocrates on necrotising fasciitis. Lancet. 1994;344:556.

2. Wilson B. Necrotizing fasciitis. Am Surg. 1952;18:416-431.

3. Trent JT, Kirsner RS. Necrotizing fasciitis. Wounds. 2002;14:284-292.

4. Giuliano A, Lewis F Jr, Hadley K, Blaisdell FW. Bacteriology of necrotizing fasciitis. Am J Surg. 1977;134:52-57.

5. Stevens DL, Besmo AL, Chambers NF, et al; Infectious Diseases Society of America. Practice guidelines for the diagnosis and management of skin and soft tissue infectious. Clin Infect Dis. 2005;41:1373-1406.

6. Wong CH, Kurup A, Wang YS, Heng KS, Tan KC. Four cases of necrotizing fasciitis caused by Klebsiella species. Eur J Clin Microbiol Infect Dis. 2004;23:403-407.

7. Whallett EJ, Stevenson JH, Wilmshurst AD. Necrotizing fasciitis of the extremity. J Plast Reconstr Aesthet Surg. 2010;63:469-473.

8. Kelesidis T, Tsiodras S. Post irradiation Klebsiella pneumoniae associated necrotizing fasciitis in the western hemisphere: a rare but life-threatening clinical entity. Am J Med Sci. 2009;338:217-224.

9. Oncul O, Erenoglu C, Top C, et al. Necrotizing fasciitis: a life threatening clinical disorder in uncontrolled type 2 diabetic patients. Diabetes Res Clin Pract. 2008;80:218-223.

10. Lin JC, Siu LK, Fung CP, et al. Impaired phagocytosis of capsular serotypes K1 or K2 Klebsiella pneumoniae in type 2 diabetes mellitus patients with poor glycemic control. J Clin Endocrinol Metab. 2006;91:3084-3087.

11. Cheng N, Tai H, Tang Y, Chang SC, Wang JT. Necrotizing fasciitis: clinical features in patients with liver cirrhosis. Br J Plast Surg. 2005;58:702-707. 
12. Turton J, Baklan H, Siu LK, Kaufmann ME, Pitt TL. Evaluation of a multiplex PCR for detection of serotypes K1, K2 and K5 in Klebsiella $s p$. and comparison of isolates within these serotypes. FEMS Microbiol Lett. 2008;284:247-252.

13. Yu WL, Fung CP, Ko WC, Cheng KC, Chuang YC. Polymerase chain reaction analysis for detecting capsule serotypes $\mathrm{K} 1$ and $\mathrm{K} 2$ of Klebsiella pneumoniae causing abscesses of the liver and other sites. J Infect Dis. 2007;195:1235-1236.

14. Brisse S, Fevre C, Passet V, et al. Virulent clones of Klebsiella pneumoniae: identification and evolutionary scenario based on genomic and phenotypic characterization. PLoS One. 2009;4:e4982.

15. Chen YT, Chang HY, Lai YC, Pan CC, Tsai SF, Peng HL. Sequencing and analysis of the large virulence plasmid pLVPK of Klebsiella pneumoniae CG43. Gene. 2004;337:189-198.

16. Cheng NC, Yu YC, Tai HC, et al. Recent trend of necrotizing fasciitis in Taiwan: focus on monomicrobial Klebsiella pneumoniae necrotizing fasciitis. Clin Infect Dis. 2012;55:930-939.

17. Ou LF, Yeh FL, Fang RH, Yu KW. Bacteriology of necrotizing fasciitis: a review of 58 cases. Chin Med J. 1993;51:271-275.

18. Decré D, Verdet C, Emirian A, et al. Emerging severe and fatal infections due to Klebsiella pneumoniae in two university hospitals in France. J Clin Microbiol. 2011;49:312-314.

19. Gunnarsson GL, Brandt PB, Gad D, Struve C, Justesen US. Monomicrobial necrotizing fasciitis in a white male caused by hypermucoviscous Klebsiella pneumoniae. J Med Microbiol. 2009;58:1519-1521.

20. Persichino J, Tran R, Sutjita M, Kim D. Klebsiella pneumoniae necrotizing fasciitis in a Latin American male. J Med Microbiol. 2012;61:1614-1616.

21. Shon AS, Bajwa R, Russo TA. Hypervirulent (hypermucoviscous) Klebsiella pneumoniae: a new and dangerous breed. Virulence. 2013;4: 107-118.

22. Ginaldi L, De Martinis M, D’Ostilio A, et al. The immune system in the elderly: II specific cellular immunity. Immunol Res. 1999;20:109-115.

23. Gevazzi G, Kraise KH. Ageing and infection. Lancet Infect Dis. 2002; 2:659-666.
24. Lee SSJ, Chen YS, Tsai HC, et al. Predictors of septic metastatic infection and mortality among patients with Klebsiella pneumoniae liver abscess. Clin Infect Dis. 2008;47:642-650.

25. McHenry CR, Piotrowski JJ, Petrinic D, Malangoni MA. Determinants of mortality for necrotizing soft-tissue infections. Ann Surg. 1995;221:558-565.

26. Liu YM, Chi CY, Ho MW, et al. Microbiology and factors affecting mortality in necrotizing fasciitis. J Microbiol Immunol Infect. 2005;38:430-435

27. Mangoni AA, Jackson SH. Age-related changes in pharmacokinetics and pharmacodynamics: basic principles and practical applications. Br J Clin Pharmacol. 2004;57:6-14.

28. Fung CP, Hu BS, Chang FY, et al. A 5-year study of the seroepidemiology of Klebsiella pneumoniae: high prevalence of capsular serotype in Taiwan and implication for vaccine efficacy. J Infect Dis. 2000;181:2075-2079.

29. Hu BS, Lau YJ, Shi ZY, Lin YH. Necrotizing fasciitis associated with Klebsiella pneumoniae liver abscess. Clin Infect Dis. 1999;29:1360-1361.

30. Lee HC, Chang YC, Yu WL, et al. Clinical implications of hypermucoviscosity phenotype in Klebsiella pneumoniae isolates: association with invasive syndrome in patients with community-acquired bacteremia. J Intern Med. 2006;259:606-614.

31. Yeh KM, Kurup A, Siu LK, et al. Capsular serotype K1 or K2 rather than magA and $\operatorname{rmpA}$ is a major virulence determinant for Klebsiella liver abscess in Singapore and Taiwan. J Clin Microbiol. 2007;45:466-471

32. Lee SS. Klebsiella pneumoniae is an emerging major pathogen in necrotizing fasciitis. Clin Infect Dis. 2012;55:940-942.

33. Pourcine F, Baudel JL, Decré D, et al. Klebsiella pneumoniae liver abscesses. Lancet Infect Dis. 2013;13:392-393.

34. Bellapianta JM, Ljungquist K, Tobin E, Uhl R. Necrotizing fasciitis. J Am Acad Orthop Surg. 2009;17:174-182.
Clinical Interventions in Aging

\section{Publish your work in this journal}

Clinical Interventions in Aging is an international, peer-reviewed journal focusing on evidence-based reports on the value or lack thereof of treatments intended to prevent or delay the onset of maladaptive correlates of aging in human beings. This journal is indexed on PubMed Central, MedLine,

\section{Dovepress}

CAS, Scopus and the Elsevier Bibliographic databases. The manuscript management system is completely online and includes a very quick and fair peer-review system, which is all easy to use. Visit http://www.dovepress. com/testimonials.php to read real quotes from published authors. 